\title{
Bioresorbable vascular scaffold: a step back thinking of the future
}

\author{
Alberto Polimeni ${ }^{1,2}$, Tommaso Gori ${ }^{1}$ \\ ${ }^{1}$ Kardiologie I, Zentrum für Kardiologie, University Medical Center Mainz and DZHK standort Rhein-Main, Mainz, Germany \\ ${ }^{2}$ Division of Cardiology, Department of Medical and Surgical Sciences, “Magna Graecia” University, Catanzaro, Italy
}

Adv Interv Cardiol 2018; 14, 2 (52): 117-119 DOI: https://doi.org/10.5114/aic.2018.76401

The introduction of coronary stents in 1986 revolutionized interventional cardiology. First introduced to address issues of acute recoil and coronary artery dissections, bare metal stents (BMS) soon proved superior to balloon-only angioplasty in randomized controlled trials $[1,2]$. Later, the introduction of stents eluting cytotoxic/ cytostatic drugs addressed the incidence of late restenosis [3] and, after another 10 years, a number of modifications to the design, polymer, eluted drug, and stent struts' geometry led to devices with improved biocompatibility, radio-opacity, radial strength, and deliverability. Despite all these improvements over the years, both BMS and drug-eluting stents (DES) have some limitations. In fact, their permanent structure hinders surgical myocardial revascularization and physiological vessel remodeling and represents a permanent possible source of inflammation, which in turn is felt to expose patients to the risk of late stent thrombosis (a non-negligible hazard with an incidence up to 1-2\% annually with first-generation DES and a mortality that may reach up to 30\%) [3]. In an attempt to minimize the long-term mechanical and biological stress caused by a permanent implant, fully bioresorbable stents (BRS) were introduced in 2012 as a novel promising approach. The aim of this new technology was to treat coronary stenosis by providing transient vessel support with drug delivery capability without the long-term limitations associated with vessel caging.

In this issue of the journal, Orlik et al. [4] report 1-year clinical outcomes with the ABSORB BRS (Abbott, Santa Clara, USA) in 138 patients with coronary artery disease. The study design is observational, comparing clinical outcomes with everolimus-eluting bioresorbable scaffolds against those with everolimus-eluting metallic DES. Propensity-score matching was used in an attempt to adjust for differences in baseline patient risk between the treat- ment groups. Their main finding was that, in terms of major adverse composite endpoints, comparable results were found between bioresorbable vascular scaffolds and DES (7.2\% vs. $11.15 \% ; p=0.17)$. The target vessel revascularization rate was $2.9 \%$ in both groups. Except for the periprocedural period, there were no deaths or myocardial infarctions in the BRS group. There was no stent thrombosis in either group.

In interpreting the data, a number of limitations must be considered. First, although propensity score matching by the investigators was generally well performed, the model used could have been more carefully constructed. Propensity score modeling should use as covariates clinical and procedural parameters that were clinically relevant for the endpoint, not only the baseline characteristics of the population. In fact, the number of stents implanted and the location of the stenosis were quite different between the groups also after propensity score matching. Moreover, a history of previous percutaneous coronary intervention $(\mathrm{PCl})$, a parameter that was not taken into account for matching, was related in previous studies to worse clinical outcome [5]. Second, the presented comparison is non-randomized, so the observed outcome differences may be due to factors other than the type of stent received. No method of adjustment can fully account for the resultant differences in baseline risk. Finally, the study is considerably underpowered $(n=138)$ for comparison in relation to clinical endpoints in general, and particularly for rarely occurring events such as stent thrombosis.

In the same issue, the paper by Briede et al. [6] reports the results of a single-center real-life registry of 2-year clinical outcomes after implantation of BRS in 187 stable angina and acute coronary syndrome patients. They report very good clinical outcomes at the 2-year follow-up 
(all-cause death 3.9\%, myocardial infarction 1.6\%, target-lesion revascularization $3.9 \%$, target-vessel revascularization $8.4 \%$, scaffold restenosis $6.0 \%$, thrombosis $1.1 \%)$. The same limitations above apply to this paper.

Collectively, these two papers reproduce earlier findings of several other groups which provided evidence of short-term safety after BRS implantation in a variety of indications. Despite these initial encouraging results in the short and mid term, larger registries with a longer follow-up showed an increase of in-scaffold thrombosis (ScT) compared with everolimus-eluting stents [7-10], an observation that has been imputed to inadequate expansion of the device, unwanted adverse biological interactions, and device dismantling [11, 12]. This evidence was confirmed in randomized trials, as the negative results of ABSORB II and AIDA at long-term follow-up $[13,14]$, confirmed by several meta-analyses $[15,16]$, led to the market withdrawal of Absorb BRS in September 2017. Given the small sample size and fortunately low incidence of scaffold thrombosis, a comparison with the results of these larger trials is impossible. In the study by Orlik et al. [4], no thrombosis was observed; in the study by Briede et al. [6], only two such events had been observed at 2 years (1.1\%). In the Absorb II trial, the rate of scaffold thrombosis was $1.5 \%$; in the ABSORB III and AIDA trials the rates of scaffold thrombosis were $1.9 \%$ and $3.5 \%$. Of note, none of these studies was powered for this endpoint. The rates of target vessel myocardial infarction in these studies were in the range of $5.5-7.3 \%$, again not outside a hypothetical confidence interval of the registries by Orlik et al. [4] and Briede et al. [6]. Finally, their rate of scaffold restenosis was in line with another registry recently published that reported in a similar cohort a rate of $6 \%$ at 2 years and $9 \%$ at 3 years [17]. Of note, since no routine angiographic follow-up was planned, these figures refer to clinical restenosis only.

Having mentioned these limitations, it is however important to try and analyze the mechanisms that might have led to improved outcomes. The good results obtained by the authors could be explained by the low percentage of ACS patients (20.9\%) and complex lesions. Further, a number of studies now show that the care taken at the time of implantation [18] (whatever one wants to call it - PSP, 5Ps, "optimal technique", etc.) is associated with a dramatic reduction in events - a factor that had been forgotten with modern DES.

For all these reasons, the authors' enthusiasm needs to be tempered with words of caution. The concept of BRS technologies remains extremely attractive, but the devices come with a long learning curve (or require attention), which many cardiologists are unwilling to respect. The concern raised about very late BRS dismantling and thrombosis, together with the lack of a clear advantage in terms of clinical efficacy, complicates the development of this otherwise promising concept. Moreover, a new generation of BRS with an optimized radial strength, a sleeker endoluminal profile, a smaller footprint, and resorption processes that do not interact with the vessel wall will likely have a favorable effect on rates of stent failure. At this time, on the basis of the available published data, treatment with BRS should only be undertaken within a registry or a study, as further data are necessary before we commit our patients to this therapy.

\section{Conflict of interest}

Tommaso Gori has received grant support and speaker's honoraria from Abbott Vascular.

\section{References}

1. Fischman DL, Leon MB, Baim DS, et al. A randomized comparison of coronary-stent placement and balloon angioplasty in the treatment of coronary artery disease. Stent Restenosis Study Investigators. N Engl J Med 1994; 331: 496-501.

2. Serruys PW, de Jaegere P, Kiemeneij F, et al. A comparison of balloon-expandable-stent implantation with balloon angioplasty in patients with coronary artery disease. Benestent Study Group. N Engl J Med 1994; 331: 489-95.

3. Garg S, Serruys PW. Coronary stents: current status. J Am Coll Cardiol 2010; 56 (10 Suppl): S1-42.

4. Orlik B, Milewski K, Derbisz K, et al. Comparison of the Absorb a bioresorbable vascular scaffold to the Xience - a durable polymer everolimus eluting metallic stent in a routine clinical practice: a propensity score-matched analysis from a multicenter registry. Adv Interv Cardiol 2018; 14: 149-56.

5. Baber U, Mehran R, Giustino G, et al. Coronary thrombosis and major bleeding after $\mathrm{PCl}$ with drug-eluting stents: risk scores from PARIS. J Am Coll Cardiol 2016; 67: 2224-34.

6. Briede I, Narbute I, Kumsars I, et al. Two-year clinical outcomes after implantation of an everolimus-eluting bioresorbable scaffold (Absorb) in stable angina and acute coronary syndrome patients. Single centre real-life registry data. Adv Interv Cardiol 2018; 14: 144-8.

7. Anadol R, Schnitzler K, Lorenz L, et al. Three-years outcomes of diabetic patients treated with coronary bioresorbable scaffolds. BMC Cardiovasc Disord 2018; 18: 92.

8. Anadol R, Dimitriadis Z, Polimeni A, et al. Bioresorbable everolimus-eluting vascular scaffold for patients presenting with non ST elevation-acute coronary syndrome: a three-years follow-up. Clin Hemorheol Microcirc 2018; 69: 3-8.

9. Gori T, Weissner M, Gönner S, et al. Characteristics, predictors, and mechanisms of thrombosis in coronary bioresorbable scaffolds: differences between early and late events. JACC Cardiovasc Interv 2017; 10: 2363-71.

10. Anadol R, Lorenz L, Weissner M, et al. Characteristics and outcome of patients with complex coronary lesions treated with bioresorbable scaffolds. Three years follow-up in a cohort of consecutive patients. Eurolntervention 2017; pii: EIJ-D-17-00410. doi: 10.4244/EIJ-D-17-00410.

11. Puricel S, Cuculi F, Weissner M, et al. Bioresorbable coronary scaffold thrombosis: multicenter comprehensive analysis of clinical presentation, mechanisms, and predictors. J Am Coll Cardiol 2016; 67: 921-31.

12. Cuculi F, Puricel S, Jamshidi P, et al. Optical coherence tomography findings in bioresorbable vascular scaffolds thrombosis. Circ Cardiovasc Interv 2015; 8: e002518. 
13. Serruys PW, Chevalier B, Sotomi Y, et al. Comparison of an everolimus-eluting bioresorbable scaffold with an everolimus-eluting metallic stent for the treatment of coronary artery stenosis (ABSORB II): a 3 year, randomised, controlled, single-blind, multicentre clinical trial. Lancet 2016; 388: 2479-91.

14. Wykrzykowska JJ, Kraak RP, Hofma SH, et al. Bioresorbable scaffolds versus metallic stents in routine PCI. N Engl J Med 2017; 376: 2319-28.

15. Polimeni A, Anadol R, Munzel T, et al. Long-term outcome of bioresorbable vascular scaffolds for the treatment of coronary artery disease: a metaanalysis of RCTs. BMC Cardiovasc Disord 2017; 17: 147.

16. Sorrentino S, Giustino G, Mehran R, et al. Everolimus-eluting bioresorbable scaffolds versus everolimus-eluting metallic stents. J Am Coll Cardiol 2017; 69: 3055-66.

17. Polimeni A, Weissner M, Schochlow K, et al. Incidence, clinical presentation, and predictors of clinical restenosis in coronary bioresorbable scaffolds. JACC Cardiovasc Interv 2017; 10: 1819-27.

18. Sorrentino S, De Rosa S, Ambrosio G, et al. The duration of balloon inflation affects the luminal diameter of coronary segments after bioresorbable vascular scaffolds deployment. BMC Cardiovasc Disord 2015; 15: 169. 